\section{LASER INDUCED DAMAGE} THRESHOLD TESTING AT HILASE

PAVEL CECH, JAN VANDA, MIHAI-GEORGE MURESAN, MARTIN MYDLAR, KATERINA PILNA, JAN BRAJER

HiLASE Centre, Institute of Physics, Academy of Sciences of the Czech Republic, Dolni Brezany, Czech Republic.

DOI : 10.17973/MMSJ.2019_12_2019118

pavel.cech@HiLASE.cz

More powerful and challenging laser systems are built to meet the need of evolving technology, reflecting demands coming from both industry and research areas. Laser damage is a key parameter for all components in such high-power laser system, establishing limits of maximum achievable energy in laser beam, and consequently the power of the system. As a value for all optical components, this is represented by laser induced damage threshold (LIDT). LIDT is a value determining highest quantity of laser radiation incident upon the optical component for which the extrapolated probability of damage is zero. In following paper is described testing station build and used at HiLASE centre to determine such value, which is necessary to build reliable and stable laser sources and produce high quality optics.

KEYWORDS

LIDT, laser, laser damage, laser testing, ISO

\section{INTRODUCTION}

High powered pulsed laser systems have evolved rapidly in recent years leading to the construction of many state-of-the-art facilities focused on fundamental research, such as ELI Beamlines, PETAL, or NIF. The knowledge gained in the development of these cutting-edge facilities and their laser systems gave rise to the popularity to such larger laser systems and made it possible to develop more compact laser systems suitable for applied research. Laser applications developed in facilities such as HiLASE have great usability in many fields of the industry as cutting, machining or surface processing. However, given the output parameters needed for such applications, it is not possible for them to be fully adopted by the industry, until commercially available laser sources, which are not experimental and challenging to service and operate. The key factor limiting development of such laser systems is the laser components ability to withstand irradiation incident upon them. This ability can be described by so-called laser induced damage threshold (LIDT), which represents the highest quantity of laser intensity or fluence incidenting on particular component, for which extrapolated probability of damage occurrence equals zero.

Depending on the environmental conditions, in general, the LIDT is a function of the material properties and the laser parameters. Bulk damage is usually observed if the electrical field strength in the bulk of the component is enhanced by scattering, selffocusing, interference or other effects [Binh 2009]. Great influence comes from defects and imperfections, such as inhomogeneity, inclusions, color centers or dislocations. Bulk damage mechanisms and damage morphologies vary depending on the bulk material [Schaffer 2001]. Similarly, such defects affecting laser damage occurring on the surface of the particular specimen. Surface damage threshold is in general mostly affected by roughness, contamination and sub-surface inclusions. In components treated with surface thin films, damage is often induced by defects or mechanical stress in the coating, contamination of the surface, or optical absorption. Damage by single laser pulses leads to destructive heating of the surface, for multiple-pulse operation reversible mechanisms induced by thermal heating and distortion can be possible, but also irreversible damage mechanisms induced by ageing, microdamage, moisture damage and generation or migrations of defects can be observed [Fornier 1996].

All mentioned effects can be related with particular specimen properties and used both for analyzing and setting threshold conditions for operating in high power lasers. With proper instrumentation, LIDT test can serve for finding operation threshold of laser system components itself, as well as for characterization of bulk materials, multilayers and surfaces [Ristau 2011].

Since LIDT is heavily dependent on the parameters of the laser beam used for LIDT testing, intended use should be reflected in test design. To cover the best practices and the most common cases, series of standards describing testing laser parameters, proper test designs and recommended methods of damage detection were developed under the International Organization for Standardization (ISO) [ISO 2011]. Following this standards, LIDT measured value should be reproducible on other ISO 21254 standard-compliant facilities, which use to be proven by roundrobin tests on witness samples.

\section{HILASE LIDT STATION}

Automated ISO compliant LIDT testing station [Vanda 2015] running in the HILASE center currently use two state-of-the-art laser sources:

First is laser called Bivoj [Pilar 2018], which is a DPSSL system based on cryogenically cooled ytterbium doped slab amplifier with wavelength of $1030 \mathrm{~nm}$, repetition rate of $10 \mathrm{~Hz}$, pulse length of $10 \mathrm{~ns}$, square top head beam profile and energy per pulse up to $10 \mathrm{~J}$. Pulse picking is in this repetition rate realized by a fast flip mirror and the beam is then passed through an attenuator consisting of a remotely controlled rotation stage with a half-wave plate and a thin film polarizer.

The second laser available is the Perla B system [Chyla 2012], which is also a DPSSL system based on ytterbium doped thin disk with wavelength of $1030 \mathrm{~nm}$, repetition rate of $1 \mathrm{kHz}$, pulse length $1.8 \mathrm{ps}$, Gaussian beam profile and energy per pulse up to $10 \mathrm{~mJ}$. Attenuator for pulse energy control is similarly like for Bivoj based on thin film polarizer, number of pulses is driven by BBO crystal Pockel's cell.

Both are directed to the LIDT station via a laser beam distribution system. With both lasers providing very high pulse energies, it is possible to measure LIDT using larger beam size, which greatly increases the measurement accuracy by diminishing the influence of pixel induced error from the beamprofiler. The beam is after attenuation focused on the sample by a focusing element, either a lens, or a concave mirror. In the beam path is a thin film sampler, which separate a non-significant part of the energy $(<1 \%)$ for the diagnostic branch. That way beam profile and energy levels can be controlled continuously during the test. Energy is measured with calibrated energy meter, beam profile is measured equidistant to the sample with a CMOS (Complementary metal-oxide-semiconductor) camera using ISO compliant characterization software.

Testing station is placed in clean room laboratory with controlled humidity, temperature and dust particle concentration with measured cleanliness of ISO class 6 . Sample mount and damage detection setup is placed in an experimental chamber designed for either vacuum up to 10-3 mBar, or for overpressure testing in non-corrosive atmosphere up to 1.4 Bar. Sample is mounted 
on a micrometric translation 2-axis stage, which is controlled remotely. Online damage detection is realized by an online camera continuously monitoring exposed site; laser scanning microscope is used for examination of the sample before and after the testing procedure.

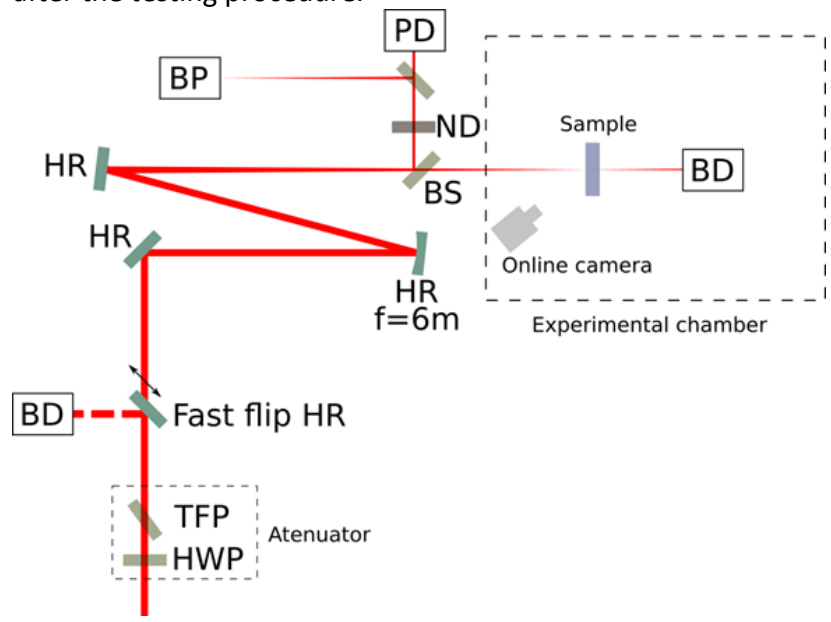

Figure 1. Experimental setup of the LIDT station. PD - photodiode; BP beam profiler; ND - filters; BS - beam splitter; HR - highly reflective mirror; BD - beam dump; TFP - thin film polarizer; HWP - half-wave plate.

This design of the LIDT station meets every requirement from the ISO 21254 standard [ISO 2011]. Laser systems used are providing beam profiles in accordance to ISO 11146, pulse-topulse energy variations in under $5 \%$, stable repetition rate and are equipped with polarization and beam quality management. Attenuator system used in the LIDT station does not affect neither the beam quality nor the polarization state. Focusing system is well documented, active area and energy density is referred to the location of the test surface, effective area is stable during the LIDT measurement and self-focusing and filamentation threshold in the test environment is not exceeded. Detectors for energy measurements are calibrated with national standards and have absolute uncertainty under $5 \%$. LIDT station is equipped with instrumentation for analyzing both temporal beam profile for effective pulse duration and spatial beam profile with spatial resolution better than $1.5 \%$ of the beam diameter. Test reports of the measurements carried out on the LIDT station contain description of techniques used.

\section{EXPERIMENT}

As a demonstration of the capabilities of the station, six LIDT measurements on thin-film coatings are presented. There were three types of substrate chosen - BK7 glass, fused silica and YAG crystal, each type having an AR coated specimen and a HR coated specimen. An undoped YAG single crystal was grown in an iridium crucible along the [111] crystallographic direction by the Czochralski method under $\mathrm{Ar}$ atmosphere. The crystal was cut into thin discs of $25 \mathrm{~mm}$ in diameter and $2.5 \mathrm{~mm}$ in thickness; surfaces were machined by single-point diamond turning. Prepared disc samples were polished on both sides $(\lambda / 10 @ 632.8$ $\mathrm{nm}$ roughness) using $\mathrm{CeO} 2$ slurry and cleaned by sulfochromic acid and deionized water in ultrasonic bath. Polished surface was inspected using laser interferometer profiler and samples were stored dust-free boxes for coating. BK7 and fused silica were purchased as pre-prepared 2" substrates packed in dust-free boxes and polished $(\lambda / 10 @ 632.8 \mathrm{~nm}$ roughness with $\mathrm{CeO} 2$ slurry.

$A R$ and HR coatings were prepared by reactive e-beam physical vapour deposition with ion beam assistance (so-called IAD technique) for the angle of incidence $0^{\circ}$. AR thin films on tested glass samples were prepared on both sides either by multilayer combination of $\mathrm{ZrO} 2$ as high refractive index material and $\mathrm{SiO} 2$ as low refractive index material; in a case of YAG substrate was $\mathrm{ZrO} 2$ substituted with $\mathrm{HfO} 2$. HR thin films on tested samples were prepared on one side either by multilayer combination $\mathrm{ZrO} 2$ and $\mathrm{SiO} 2$. There was no protective or adhesion layer introduced. Coated samples were packed in clean room, dustprove sealed and sent for damage threshold tests. When unpacked, all crystal samples were checked on laser scanning microscope for surface cleanliness, surface defects and roughness/flatness.

For the test was used Bivoj laser system. Tested sample was fixed on 2-axis computer controlled micrometric translation stage, beam diameter on the sample was then set with the HR spherical mirror and measured with the CMOS (Complementary metaloxide semiconductor) beam profiler. Laser beam passes through attenuator, where s-polarized beam is deflected to the beam dump. Only p-polarized component of the beam was interacting with the tested sample. Beam energy was set up with the polarizer and half wave plate and continuously monitored with the power meter. Half-wave plate was calibrated in discrete steps $1^{\circ}$, at each position was energy measured with according tolerances; during the test was energy set in the same steps. Fluence was then calculated from particular energies and beam diameter acording to ISO 11146-2, which was continuously monitored by beamprofiler in equivalent distance from focusing mirror. Beam parameters are in table 1 , measured beam profile is shown in figure 2. Duration of the exposure was precisely ensured with the fast flip mirror, which was synchronized with laser. Sample was continuously monitored during the exposure with the CMOS camera. In the case of damage the testing process was interrupted. After the measurement samples were scanned on a Normanski-type laser microscope and all of the irradiated sites were checked for damage that was potentially undetected during the measurement.

\begin{tabular}{|c|c|}
\hline $\begin{array}{l}\text { Spatial beam shape in } \\
\text { target plane }\end{array}$ & $\begin{array}{l}\text { Near-Gaussian, round, } \\
\text { ellipticity } 95 \%\end{array}$ \\
\hline $\begin{array}{l}\text { Measured beam } \\
\text { surface }(1,414 \mathrm{~s})\end{array}$ & $0.000832 \mathrm{~cm}$ \\
\hline $\begin{array}{l}\text { Gaussian fit beam } \\
\text { diameter }\left(1 / \mathrm{e}^{2}\right)\end{array}$ & $460 \mu \mathrm{m}$ \\
\hline Angle of incidence & $1^{\circ}$ \\
\hline Focusing system & $\begin{array}{l}\text { Parabolic dielectric mirror } \mathrm{f} \sim \\
6000 \mathrm{~mm}\end{array}$ \\
\hline Environment & $\begin{array}{l}\text { Ambient air, ISO class } 7 \\
\text { clean }\end{array}$ \\
\hline Temperature/Humidity & $21.1^{\circ} \mathrm{C} / 47 \%$ \\
\hline
\end{tabular}

Table 1. Beam parameters measured in a plane of incidence. 

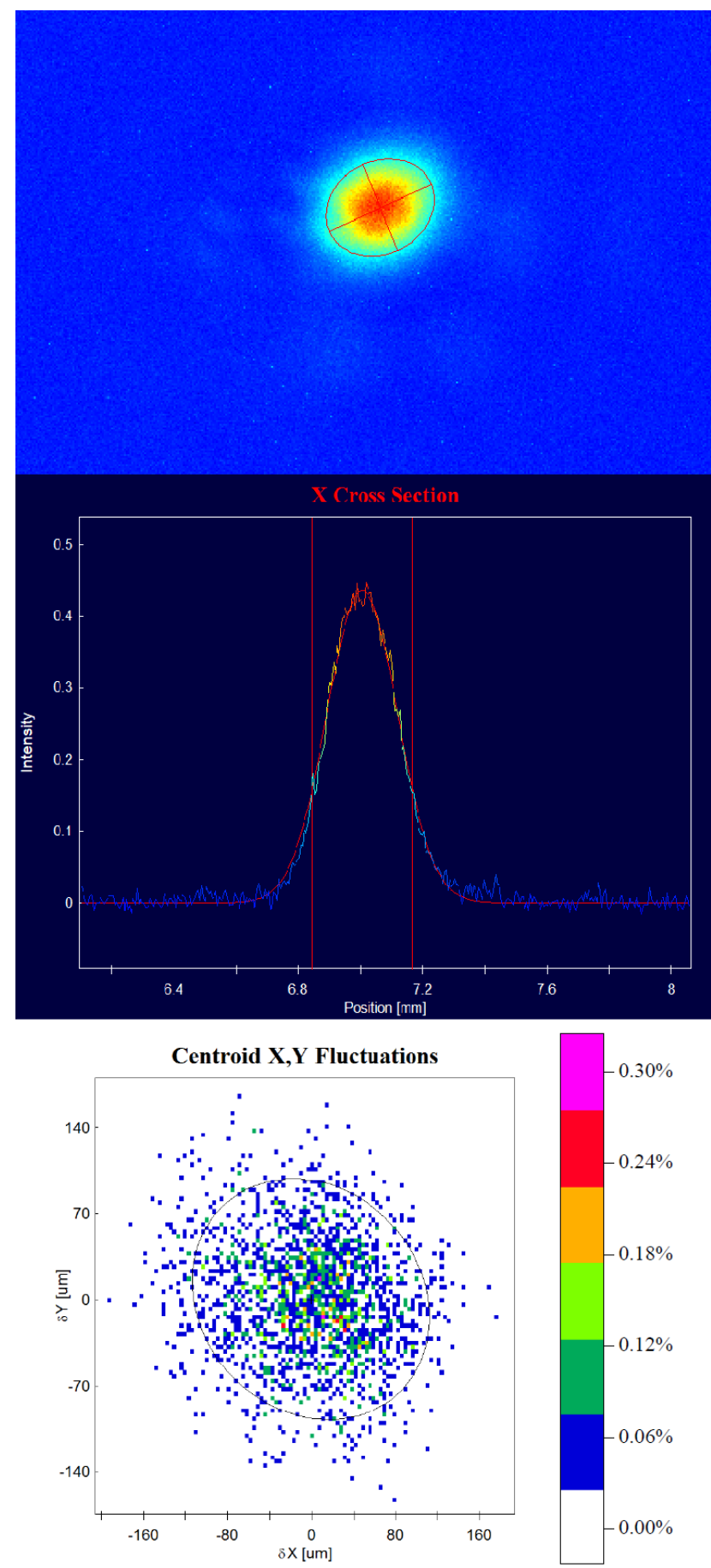

Figure 2. Spatial profile in target plane: $2 \mathrm{D}$ beam profile sigma $1,414 \mathrm{~s}$, Gaussian profile fit $1 / \mathrm{e} 2$ and pointing stability for 2000 pulses.

Maximum test time is given by the sum of total number of pulses and repetition rate of used laser shots with no damage occurring during the test; time needed for sample motion between neighboring test sites and time needed to set proper energy. For presented samples are test parameters given in table 2. Maximum test time $T_{\max }$ is calculated according to equation 1 , where $s$ is number of pulses, $N$ is number of sites, frep laser repetition rate, $t_{t}$ is average travel time between sites, $t_{E}$ time needed to set the energy and $Q_{E}$ number of energy levels.

$$
\begin{aligned}
\boldsymbol{T}_{\text {max }}=\left(\frac{s \cdot \boldsymbol{N}}{f_{\text {rep }}}\right)+ & \left(\boldsymbol{N} \cdot \boldsymbol{t}_{t}\right)+\left(\boldsymbol{t}_{E} \cdot Q_{E}\right)= \\
& =\left(\frac{\mathbf{1 0 0 0} \cdot \mathbf{1 0 0}}{\mathbf{1 0}}\right)+(\mathbf{1 0 0} \cdot \mathbf{1 . 7}) \\
& +(\mathbf{0 . 9} \cdot \mathbf{1 0})=10179[s]
\end{aligned}
$$

\begin{tabular}{|l|l|}
\hline $\begin{array}{l}\text { Sample dimensions } \\
\text { (glass / YAG } \\
\text { substrate) }\end{array}$ & $\begin{array}{l}\text { Round, } 50.8 \mathrm{~mm} / \text { Round, } 25 \\
\mathrm{~mm}\end{array}$ \\
\hline $\begin{array}{l}\text { Tested aperture } \\
\text { (glass / YAG } \\
\text { substrate) }\end{array}$ & $40 \mathrm{~mm} / 21 \mathrm{~mm}$ \\
\hline $\begin{array}{l}\text { Test site size (glass } \\
\text { / YAG substrate) }\end{array}$ & $3.2 \mathrm{~mm} / 1.1 \mathrm{~mm}$ \\
\hline $\begin{array}{l}\text { Number of test sites } \\
\text { available (glass / } \\
\text { YAG) }\end{array}$ & $121 / 101$ \\
\hline $\begin{array}{l}\text { Number of test sites } \\
\text { used N }\end{array}$ & 100 \\
\hline \begin{tabular}{l} 
Sites matrix \\
\hline Pulses per site s
\end{tabular} & 1000 \\
\hline $\begin{array}{l}\text { Number of energy } \\
\text { levels QE }\end{array}$ & 10 \\
\hline $\begin{array}{l}\text { Online damage } \\
\text { detection }\end{array}$ & online camera \\
\hline $\begin{array}{l}\text { Offline damage } \\
\text { detection }\end{array}$ & laser scanning microscope \\
\hline
\end{tabular}

Table 2. Test parameters applied on measured samples.

Test results are presented in table 3, and figures 3,4 , and 5 . Table contains a summary of tested samples with respective laser induced damage threshold extrapolated from measured values. Figures contains respective graphs of damage probabilities with extrapolated damage probability curves and microscope images of damage craters typical for respective samples.

\begin{tabular}{llll}
$\begin{array}{l}\text { Coating } \\
\text { type }\end{array}$ & $\begin{array}{l}\text { Coating } \\
\text { material }\end{array}$ & Substrate & $\begin{array}{l}\text { LIDT } \\
{\left[\mathrm{Jcm}^{-2}\right]}\end{array}$ \\
\hline \multirow{3}{*}{ AR } & $\mathrm{ZrO}_{2} / \mathrm{SiO}_{2}$ & $\mathrm{BK} 7$ & 28.3 \\
& $\mathrm{ZrO}_{2} / \mathrm{SiO}_{2}$ & FS & 16.7 \\
\cline { 2 - 2 }$/ \mathrm{SiO}_{2}$ & YAG & 25.1 \\
\hline \multirow{2}{*}{$\mathrm{HR}$} & $\mathrm{ZrO}_{2} / \mathrm{SiO}_{2}$ & $\mathrm{BK} 7$ & 17.1 \\
& $\mathrm{ZrO}_{2} / \mathrm{SiO}_{2}$ & FS & 13.1 \\
& $\mathrm{ZrO}_{2} / \mathrm{SiO}_{2}$ & YAG & 11.9 \\
\hline
\end{tabular}

Table 3. Laser induced damage threshold values.
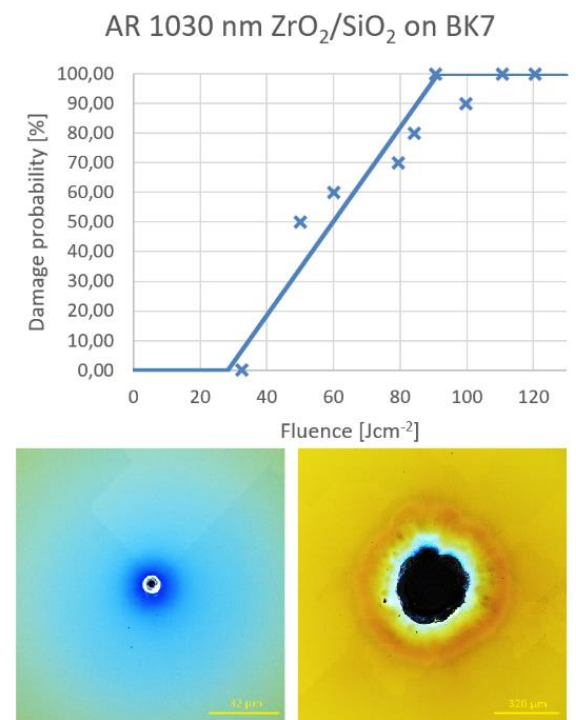

Figure 3. Dependency of damage probability on fluence for BK7 substrate with $\mathrm{ZrO}_{2} / \mathrm{SiO}_{2} \mathrm{AR}$ coating and examples of damaged spots. 
HR $1030 \mathrm{~nm} \mathrm{ZrO} / \mathrm{SiO}_{2}$ on BK7
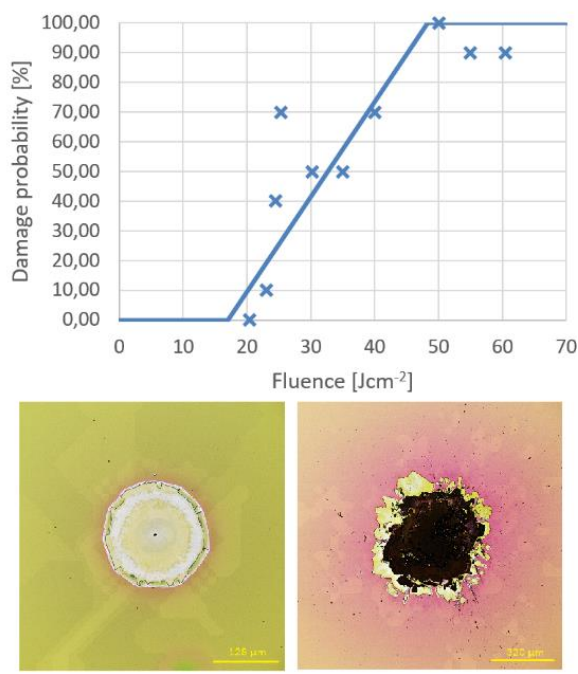

Figure 3. Dependency of damage probability on fluence for BK7 substrate with $\mathrm{ZrO}_{2} / \mathrm{SiO}_{2} \mathrm{HR}$ coating and examples of damaged spots.

\section{AR $1030 \mathrm{~nm} \mathrm{ZrO} / \mathrm{SiO}_{2}$ on FS}
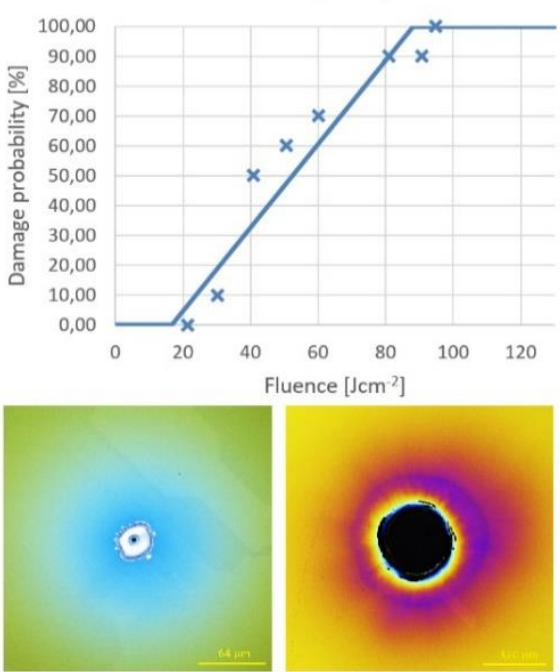

Figure 4. Dependency of damage probability on fluence for fused silica substrate with $\mathrm{ZrO}_{2} / \mathrm{SiO}_{2}$ AR coating and examples of damaged spots.

$\mathrm{HR} 1030 \mathrm{~nm} \mathrm{ZrO} / \mathrm{SiO}_{2}$ on FS

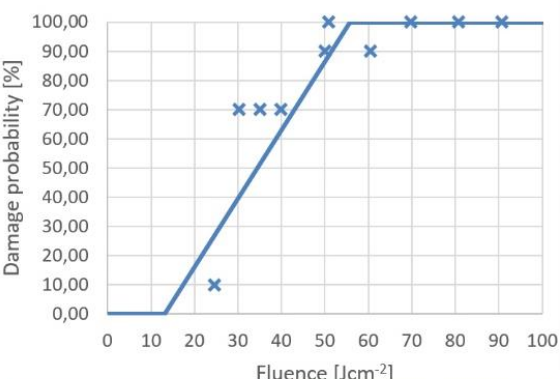

nce $\left[\mathrm{cm}^{-2}\right]$

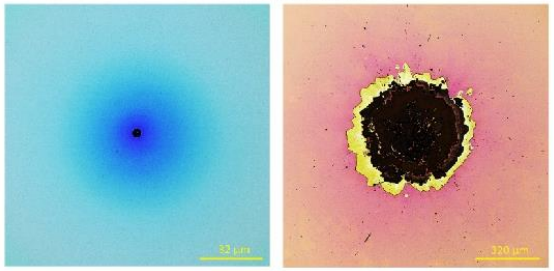

Figure 5. Dependency of damage probability on fluence for fused silica substrate with $\mathrm{ZrO}_{2} / \mathrm{SiO}_{2} \mathrm{HR}$ coating and examples of damaged spots.

\section{AR $1030 \mathrm{~nm} \mathrm{HfO} / \mathrm{SiO}_{2}$ on YAG}
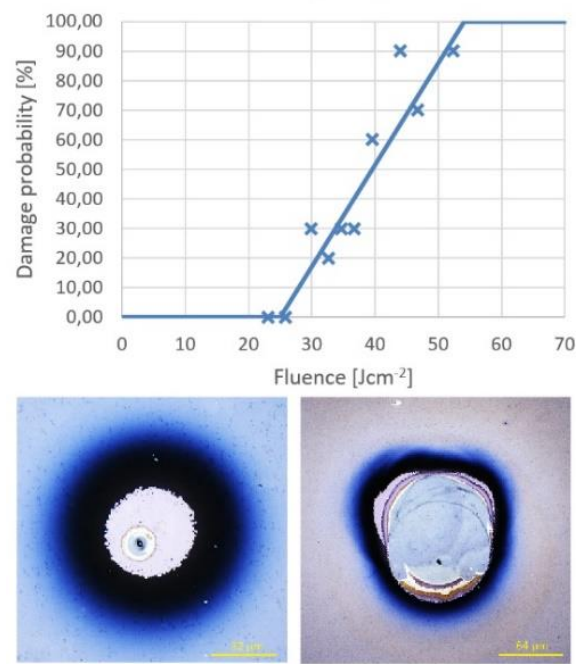

Figure 6. Dependency of damage probability on fluence for YAG substrate with $\mathrm{HfO}_{2} / \mathrm{SiO}_{2}$ AR coating and examples of damaged spots.

HR $1030 \mathrm{~nm} \mathrm{ZrO} / \mathrm{SiO}_{2}$ on YAG
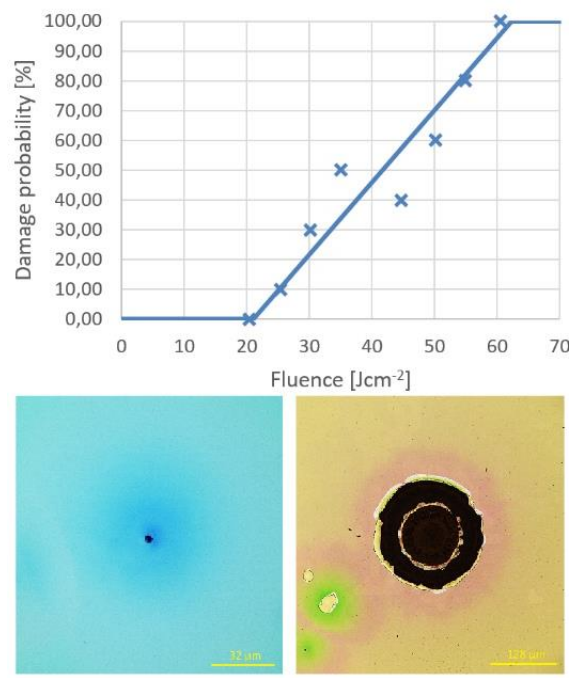

Figure 7. Dependency of damage probability on fluence for YAG substrate with $\mathrm{ZrO}_{2} / \mathrm{SiO}_{2} \mathrm{HR}$ coating and examples of damaged spots.

Measured values are in good agreement with expected results, based on broadly tested similar dielectric structured produced by different vendors. Damage probability increases linearly with fluence, suggesting that there is no influence of extrinsic factors as coatings contaminants, surface irregularities or beam energy fluctuations. Damage morphologies are regular craters with collar delamination typical for damage caused by nanosecond pulses. There was no evidence of false damage detections (e. g. sites marked as damaged but with no crater or other surface defect linked with high energy laser exposure) in tests as well as no undetected damages/craters revealed with microscope analysis after the test.

\section{CONCLUSION}

The laser induced damage threshold testing station designed at HiLASE centre was presented. It has been shown that it is fully compliant with the standards provided by the ISO in standards 21254 series. Samples of three different substrate materials with AR/HR oxide-based dielectric coatings were tested for their LIDT value, in order to demonstrate the capabilities of the station. Presented techniques can be applied not only to 
transparent dielectrics; but similar procedures can be employed also to metallic materials and non-transparent coatings or paints. Such results can be and are successfully used for setting proper parameters in laser machining, drilling, texturizing or cleaning of particular surfaces.

\section{ACKNOWLEDGMENTS}

Funding: This work was supported by European Structural and Investing Funds, Operational Programme Research, Development and Education (Grant agreement NO CZ.02.1.01/0.0/0.0/15_006/0000674) and by the Ministry of Education, Youth and Sports of the Czech Republic (Programmes NPU I-Project no. LO1602 and Large Research Infrastructure Project No. LM2015086).

\section{REFERENCES}

[Binh 2009] Binh, T. D., Smith, A. V. Bulk optical damage thresholds for doped and undoped, crystalline and ceramic yttrium aluminum garnet. Applied Optics, 2009, Vol. 48, No. 18, pp 3509-3514.

[Schaffer 2001] Schaffer C. B., Brodeur, A. Laser-induced breakdown and damage in bulk transparent materials induced by tightly focused femtosecond laser pulses. Measurement Science and Technology, 2001, Vol. 12, No. 11, pp 1784-1794.
[Fornier 1996] Fornier, A., Cordillot, C. Laser conditioning of optical coatings: A statistical study of defects by atomic force microscopy. Twenty-seventh annual Boulder damage symposium, 1996, CONF-9510106Vol.2714.

[Ristau 2011] Ristau, D. Laser-induced damage in optical materials. CRC Press 2014. ISBN 9781138199569.

[ISO 2011] ISO 21254 series. [Lasers and laser-related equipment - Test methods for laser-induced damage threshold]. Geneva, ISO copyright office, 2011.

[Vanda 2015] Vanda, J. Progress in design of advanced LIDT station in HiLASE project. Optics and Measurement Conference, 2014. Proc. SPIE 9442, 94421E.

[Pilar 2018] Pilar, J., De Vido, M., et al. Characterization of Bivoj/DiPOLE 100: HiLASE 100-J/10-Hz diode pumped solid state laser. Solid State Lasers XXVII: Technology and Devices, 2018. Proc. SPIE 10511, 105110X.

[Chyla 2012] Chyla, M., Smrz, M., et al. High energy, picosecond regenerative thin disk amplifier at $1 \mathrm{kHz}$. Solid state lasers XXI: Technology and devices, 2012. 8235, $82351 \mathrm{~W}$.

\section{CONTACTS:}

Bc. Pavel Čech

HiLASE Centre, Institute of Physics, Academy of Sciences of the Czech Republic, Za Radnici 828, Dolni Brezany, 25241, Czech Republic.

Tel.: +420 314007 742, pavel.cech@HiLASE.cz, https://www.hilase.cz/ 